\title{
Deubiquitylating enzyme USP9x regulates radiosensitivity in glioblastoma cells by Mcl-1-dependent and -independent mechanisms
}

\author{
F Wolfsperger ${ }^{1,5}$, SA Hogh-Binder ${ }^{1,5}$, J Schittenhelm ${ }^{2}$, T Psaras ${ }^{3}$, V Ritter ${ }^{4}$, L Bornes ${ }^{4}$, SM Huber ${ }^{1}$, V Jendrossek ${ }^{4}$ and J Rudner ${ }^{*, 4}$
}

Glioblastoma is a very aggressive form of brain tumor with limited therapeutic options. Usually, glioblastoma is treated with ionizing radiation (IR) and chemotherapy after surgical removal. However, radiotherapy is frequently unsuccessful, among others owing to resistance mechanisms the tumor cells have developed. Antiapoptotic B-cell leukemia (Bcl)-2 family members can contribute to radioresistance by interfering with apoptosis induction in response to IR. Bcl-2 and the closely related Bcl-xL and Mcl-1 are often overexpressed in glioblastoma cells. In contrast to Bcl-2 and Bcl-xL, Mcl-1 is a short-lived protein whose stability is closely regulated by ubiquitylation-dependent proteasomal degradation. Although ubiquitin ligases facilitate degradation, the deubiquitylating enzyme ubiquitin-specific protease 9x (USP9x) interferes with degradation by removing polyubiquitin chains from Mcl-1, thereby stabilizing this protein. Thus, an inability to downregulate Mcl-1 by enhanced USP9x activity might contribute to radioresistance. Here we analyzed the impact of USP9x on Mcl-1 levels and radiosensitivity in glioblastoma cells. Correlating Mcl-1 and USP9x expressions were significantly higher in human glioblastoma than in astrocytoma. Downregulation of Mcl-1 correlated with apoptosis induction in established glioblastoma cell lines. Although Mcl-1 knockdown by siRNA increased apoptosis induction after irradiation in all glioblastoma cell lines, USP9x knockdown significantly improved radiation-induced apoptosis in one of four cell lines and slightly increased apoptosis in another cell line. In the latter two cell lines, USP9x knockdown also increased radiation-induced clonogenic death. The massive downregulation of Mcl-1 and apoptosis induction in A172 cells transfected with USP9x siRNA shows that the deubiquitinase regulates cell survival by regulating Mcl-1 levels. In contrast, USP9x regulated radiosensitivity in Ln229 cells without affecting Mcl-1 levels. We conclude that USP9x can control survival and radiosensitivity in glioblastoma cells by Mcl-1-dependent and Mcl-1-independent mechanisms.

Cell Death and Disease (2016) 7, e2039; doi:10.1038/cddis.2015.405; published online 14 January 2016

Along with surgery, radiotherapy, and chemotherapy are the main treatment options of tumors. While the former aims to remove the tumor bulk mass, the latter two intend to neutralize remaining tumor cells. Ionizing radiation (IR) exerts its cytotoxic effects by inducing cell death. One form of specific cell death induced by IR is intrinsic apoptosis, which is regulated by members of the $\mathrm{B}$-cell leukemia (Bcl)-2 protein family. ${ }^{1}$

The $\mathrm{Bcl}-2$ protein family consists of protective antiapoptotic and pro-apoptotic members, which keep each other in check by antagonizing each other's function. ${ }^{2}$ The activation of pro-apoptotic multidomain proteins Bax and Bak is essential to induce mitochondrial outer membrane permeabilization, resulting in the release of cytochrome $\mathrm{C}$ and other apoptotic factors into the cytosol where, in turn, caspases become activated. Antiapoptotic $\mathrm{Bcl}-2$ family members prevent the activation of Bax and Bak either by direct interaction or indirectly by sequestering pro-apoptotic $\mathrm{BH}$-only proteins $\mathrm{Bim}$ and Bid that are required to activate Bax and Bak. Other
BH3-only proteins are also able to bind to antiapoptotic proteins, thereby releasing Bax and Bak from their inhibitory complexes with antiapoptotic proteins. Changing the balance between anti- and pro-apoptotic Bcl-2 family members can shift the cells toward survival or apoptosis, depending on whether the protective or the detrimental proteins dominate.

Bcl-2 itself, Bcl-xL, and myeloid cell lymphoma-1 (Mcl-1) belong to the antiapoptotic proteins of the Bcl-2 family. They are often overexpressed in tumor cells and are associated with increased resistance to apoptosis induction in response to radio- and chemotherapy. 3,4 As more than one of the protective proteins can be upregulated in tumors, the neutralization of all antiapoptotic proteins is needed to successfully induce apoptosis. Blocking the antiapoptotic function of $\mathrm{Bcl}-2 / \mathrm{Bcl}-\mathrm{xL}$ by inhibitors mimicking $\mathrm{BH} 3-o n l y$ proteins, such as ABT737 and ABT263, can induce apoptosis in cells with low Mcl-1 levels but has no effect on cells with high Mcl-1 levels. ${ }^{5-7}$ In contrast, specific inhibitors targeting Mcl-1 have been insufficiently described until now. However, Mcl-1

\footnotetext{
${ }^{1}$ Department of Radiation Oncology, University of Tuebingen, Tuebingen, Germany; ${ }^{2}$ Department of Neuropathology, Institute of Pathology and Neuropathology, University of Tuebingen, Tuebingen, Germany; ${ }^{3}$ Department of Neurosurgery, University of Tuebingen, Tuebingen, Germany and ${ }^{4}$ Institute for Cell Biology, University Hospital Essen, Essen, Germany

*Corresponding author: J Rudner, Institute for Cell Biology, University Hospital Essen, Virchowstrasse 173, Essen 45147, Germany. Tel: +49 201 7232614; Fax: +49 201 7235904; E-mail: justine.rudner@uk-essen.de

${ }^{5}$ These authors contributed equally to this work.

Abbreviations: Bcl-2/-xL, B-cell leukemia-2/xL; BH3, Bcl-2 homology domain 3; GSK-3 $\beta$, glycogen synthase kinase GSK-3 $\beta$; IR, ionizing radiation; Mcl-1, myeloid cell leukemia sequence 1; Mule, Mcl-1 ubiquitin ligase $\mathrm{E} 3$; $\beta$-TrCP, $\beta$-transducin repeat-containing protein; USP9x, ubiquitin-specific protease $9 \mathrm{x}$

Received 02.4.15; revised 13.11.15; accepted 11.12.15; Edited by G Dewson
} 
availability might be modulated by targeting pathways that regulate $\mathrm{Mcl}-1$ stability.

In contrast to $\mathrm{Bcl}-2$ and $\mathrm{Bcl}-\mathrm{xL}, \mathrm{Mcl}-1$ is a relatively shortlived protein., 8 Usually, $\mathrm{Mcl}-1$ is quickly ubiquitylated by specific ubiquitin ligases and targeted for proteasomal degradation. Phosphorylation of $\mathrm{Mcl}-1$, for example by glycogen synthase kinase GSK-3 $\beta$, can accelerate this degrading process, ${ }^{10,11}$ whereas deubiquitinases counteract it by removing the polyubiquitin chain, thereby stabilizing the short-lived protein. The ubiquitin-specific protease 9x (USP9x) was recently identified as a Mcl-1 specific deubiquitinase. ${ }^{12}$ However, the circumstances under which USP9x regulates Mcl-1 stability are not well understood. Schwickart et al. ${ }^{12}$ showed that USP9x levels correlated with Mcl-1 levels, suggesting a constitutive regulation of $\mathrm{Mcl}-1$ levels by the deubiquitinase. In contrast, our recent results showed no effect of USP9x on Mcl-1 levels in healthy Jurkat cells, but an accelerated IR-induced Mcl-1 degradation was detected when USP9x was knocked down. ${ }^{9}$ This indicates that the association of USP9x with $\mathrm{Mcl}-1$ is regulated by a yet unknown mechanism in response to irradiation.

In the present study, we aimed to analyze the impact of USP9x on $\mathrm{Mcl}-1$ and cell survival in glioblastoma cell lines. Glioblastoma is not only the most common but also a very aggressive form of brain tumor that are primarily removed by surgery as radically as possible and consecutively treated with radiochemotherapy, if the patient's condition allows for adjuvant therapy. ${ }^{13}$ Despite the multimodal treatment, the median patient survival is below 1.5 years. Comparing human grade III astrocytoma with grade IV glioblastoma samples, we could show that Mcl-1 and USP9x are upregulated during tumor progression. Furthermore, we examined four established (A172, U373, Ln229, T98G) and two primary (LKI, WKI) glioblastoma cell lines that differ in their ability to downregulate Mcl-1 and induce apoptosis in response to IR. Analyzing A172 and U373 cells more closely, we detected an increased $\mathrm{Mcl}-1$ ubiquitylation that correlated with a reduced $\mathrm{Mcl}-1$ stability $48 \mathrm{~h}$ after irradiation in U373 cells, but not in A172 cells. Moreover, Mcl-1 knockdown sensitized A172, Ln229, and T98G cells to IR-induced apoptosis, suggesting that $\mathrm{Mcl}-1$ is an important factor increasing glioblastoma cell survival after irradiation. In contrast, USP9x knockdown slightly increased apoptosis in IR-resistant A172 cells and significantly in Ln229 cells and reduced clonogenic survival after irradiation only on these two cell lines. Although USP9x knockdown reduced Mcl-1 levels and increased apoptosis in A172 cells, USP9x regulated radiosensitivity independently of $\mathrm{Mcl}-1$ in Ln229 cells.

Our results show a different requirement of USP9x in the control of glioblastoma cell survival and radiosensitivity.

\section{Results}

Mcl-1 and USP9x are upregulated during tumor progression. In the first set of experiments, we examined the expression of $\mathrm{Mcl}-1$ and USP9x in astrocytoma (WHO grade III) and glioblastoma (WHO grade IV) (Figure 1). Immunohistochemical analysis shows that number of Mcl-1- and USP9x-positive cells and staining intensity were significantly upregulated in glioblastoma compared with astrocytoma (Figure 1b). Median immune reactivity score (IRS) of Mcl-1 increased from $0.92 \pm 0.40$ (95\% from 0.13 to $1.71, n=38$ ) in grade III astrocytoma to $5.23 \pm 0.43$ (95\% from 4.38 to $6.08, n=33$ ) in glioblastoma, whereas IRS of USP9x increased from $3.24 \pm 0.42$ (95\% from 2.39 to $4.08, n=42)$ in astrocytoma to $4.91 \pm 0.41$ (95\% from 4.10 to $5.73, n=45)$ in glioblastoma. A more detailed mosaic plot analysis of $\mathrm{Mcl}-1$ and USP9x IRS shows that Mcl-1 was upregulated in more glioblastoma tissue samples and to a greater extent than USP9x (Supplementary Figure S1). Yet, Mcl-1 and USP9x IRS correlated moderately but significantly in grade IV glioblastoma (Spearman correlation, $\rho=0.47$, $P=0.0063)$, indicating a coincidental upregulation of $\mathrm{Mcl}-1$ and USP9x.

IR-induced downregulation of Mcl-1 correlates with apoptosis induction. Previous experiments have shown the effect of USP9x on Mcl-1 in irradiated Jurkat lymphoma cells. ${ }^{9}$ Thus, we compared the protein levels of USP9x, Mcl-1 and several other Bcl-2 family members in Jurkat cells, four established (A172, Ln229, T98G, U373), and two primary (WKI, LKI) glioblastoma cell lines (Figure 2). All four glioblastoma cell lines expressed USP9x as well as antiapoptotic $\mathrm{Mcl}-1, \mathrm{Bcl}-2, \mathrm{Bcl}-\mathrm{xL}$, and pro-apoptotic Bax, Bak, Noxa, Puma, and Bad (Figure 2a). The protein levels of USP9x and Mcl-1 were slightly but insignificantly higher in five of six glioblastoma cell lines than in Jurkat cells (Figure 2b). Although all glioblastoma cell lines expressed pro-apoptotic Bax at similar levels, the levels of the other pro- and antiapoptotic proteins greatly differed between the cell lines (Figure 2a).

Next, we irradiated glioblastoma cells with $10 \mathrm{~Gy}$ and determined dissipation of mitochondrial membrane potential $(\triangle \Psi \mathrm{m})$ and DNA degradation (sub G1 population) by flow cytometry (Figure $3 a$ and $b$ ) to analyze radiation-induced cell death and apoptosis, respectively. Although $\Delta \Psi_{\mathrm{m}}$ dissipation and DNA fragmentation were hardly increased in A172, Ln229, and LKI cells in response to IR, irradiation effectively increased the cell population with dissipated $\Delta \Psi_{\mathrm{m}}$ and fragmented DNA in a time-dependent manner in U373 cells and, to a lesser extent, in T98G and WKI cells. Similar results were obtained by measuring cell death using an exclusion dye assay (Supplementary Figure S3).

Western blot analysis clearly showed caspase-3 and PARP cleavage in U373 and T98G cells and weaker caspase-3 and PARP cleavage in WKI cells, indicating that IR induced caspase-dependent apoptosis in U373, T98G, and WKI cells but not in A172, Ln229, and LKI cells (Figure 3c).

As members of the $\mathrm{Bcl}-2$ protein family regulate the mitochondrial homeostasis and the intrinsic apoptosis pathway in response to $I R,{ }^{1,14}$ up- and downregulation of those proteins might be responsible for the IR-induced apoptosis in the three glioblastoma cell lines. Therefore, we analyzed the protein levels of different $\mathrm{Bcl}-2$ family members in response to IR (Figure 3d). Although levels of antiapoptotic $\mathrm{Bcl}-2$ and $\mathrm{Bcl}-\mathrm{xL}$ did not change after irradiation in all six cell lines, IR-induced downregulation of $\mathrm{Mcl}-1$ correlated with caspase-3 activation in U373, T98G, and WKI cells. Levels of the $\mathrm{Mcl}$-1-regulating deubiquitylating enzyme USP9x were 
a

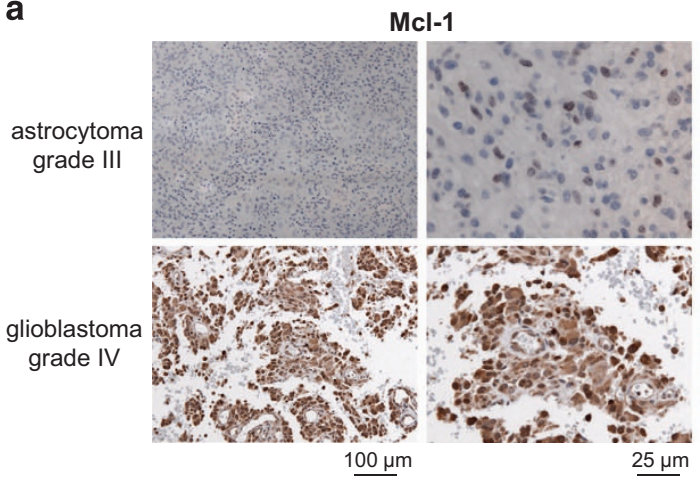

Mcl-1

b

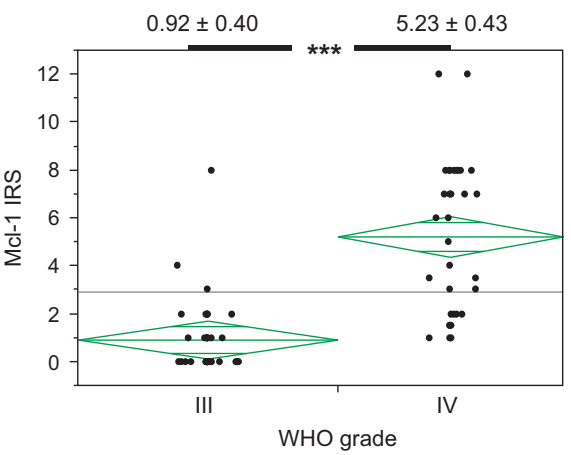

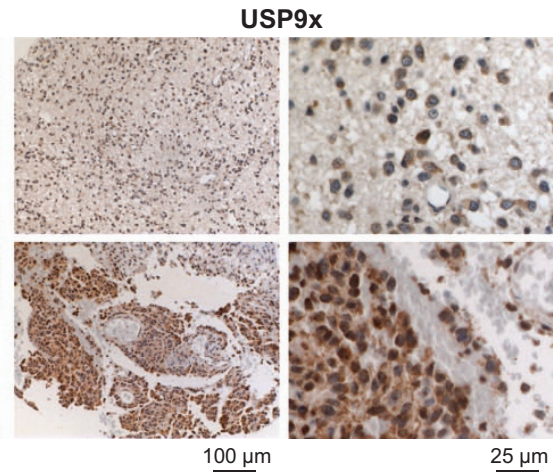

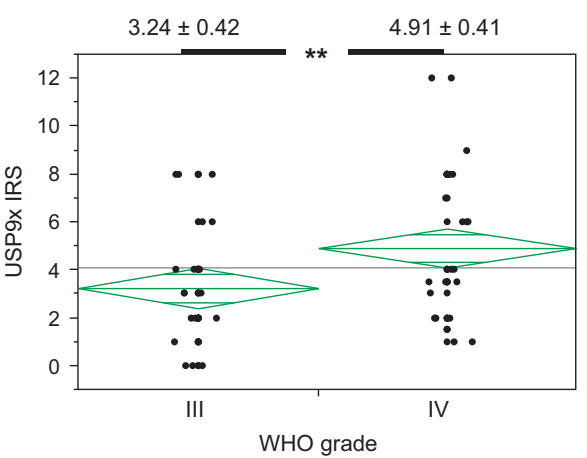

Figure 1 Mcl-1 and USP9x expression was increased in highly malignant glioblastoma. Mcl-1 and USP9x protein expressions were examined in human astrocytoma (WHO grade III) and glioblastoma (WHO grade IV) tissue samples by immunohistochemical staining. (a) Representative tissue samples stained with Mcl-1 or USP9x antibodies are shown in two magnifications. (b) Staining intensity and quantity were analyzed, and the combined immunoreactive score (IRS) was calculated for Mcl-1 (right panel) and USP9x (left panel). Median IRS \pm S.D. is shown above the respective group and staining. ${ }^{\star *} P<0.01,{ }^{* \star *} P<0.001$. Mcl-1 and USP9x expressions were significantly higher in glioblastoma than in astrocytoma

only slightly increased by IR in Ln229 cells and not affected in the other five cell lines. The pro-apoptotic Bcl-2 family members were regulated differently in response to IR in the six glioblastoma cell lines, but their regulation did not correlate with apoptosis induction.

IR reduced Mcl-1 stability in U373 cells. We selected IR-resistant A172 cells and IR-sensitive U373 cells to further analyze $\mathrm{Mcl}-1$ ubiquitylation and stability. As phosphorylation of Mcl-1 at serine 163 is associated with an accelerated degradation rate, the phosphorylation status was analyzed by western blot (Figure 4a). Increased phospho-Mcl-1 levels were detected in A172 cells 48-72 h after IR. In contrast, the $40 \mathrm{kDa}$ form of phosphorylated $\mathrm{Mcl}-1$ decreased in U373 cells $48-72 \mathrm{~h}$ following irradiation, but a shift of phosphorylated Mcl-1 was clearly visible, indicating a post-translational modification. Such a modification can be ubiquitylation, which has been associated with an increased degradation rate before. ${ }^{10,11}$ Thus, we precipitated $\mathrm{Mcl}-1$ to analyze its ubiquitylation by western blot (Figure 4b). Mcl-1 ubiquitylation was not affected in A172 cells, but was clearly increased in U373 cells $48 \mathrm{~h}$ after irradiation. Further experiments showed that more Mcl-1 co-precipitated with USP9x in A172 cells after irradiation, whereas an increased association of $\mathrm{Mcl}-1$ with USP9x was not observed in irradiated U373 cells (Figure 4c). Levels of Mcl-1, USP9x, and ubiquitylated proteins in whole-cell lysates that were used for both precipitation experiments are shown in supplementary figure (Supplementary Figure S5A).

We also analyzed the protein stability of Mcl-1 in A172 and U373 cells $48 \mathrm{~h}$ after irradiation and in non-irradiated cells. Mcl-1 was degraded at similar rates in non-irradiated and irradiated A172 cells (Figure 4d). In contrast, the half-life time significantly decreased in U373 cells after IR (Figure 4e). Moreover, comparing Mcl-1 stability in both non-irradiated cell lines, Mcl-1 was degraded slightly but insignificantly faster in U373 than in A172 cells (Supplementary Figure S5B).

Summarized, our results suggest that Mcl-1 stability is regulated by different mechanisms in irradiated A172 and U373 glioblastoma cells.

Mcl-1 and USP9x affect cell viability in glioblastoma cells. In previous publications, a stabilizing effect of deubiquitinase USP9x on Mcl-1 was described. ${ }^{12,15,16}$ Therefore, USP9x and $\mathrm{Mcl}-1$ were downregulated by siRNA in glioblasoma cells (Figure 5). USP9x knockdown resulted in decreased Mcl-1 levels in A172 and less strikingly in U373 cells, but did not change Mcl-1 levels in Ln299 and T98G cells (Figure $5 \mathrm{a}$ ). Neither $\mathrm{Bcl}-2$ nor $\mathrm{Bcl}-\mathrm{xL}$ levels were affected by transfection.

The lowered Mcl-1 levels might result in reduced cell survival due to increased apoptosis. To examine the effect of USP9x and Mcl-1 knockdown on apoptosis induction, DNA fragmentation was analyzed by flow cytometry $72 \mathrm{~h}$ following transfection. Downregulation of USP9x markedly increased 

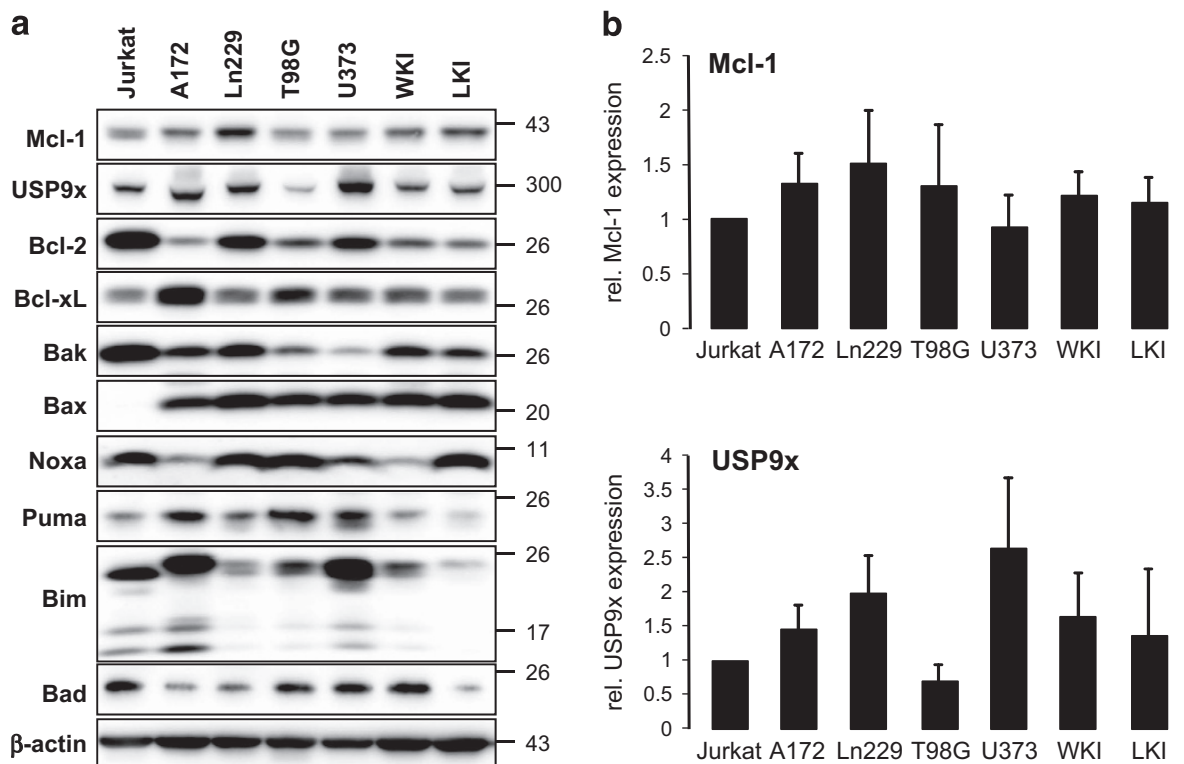

Figure 2 Protein levels of different Bcl-2 family members and the deubiquitinase USP9x in glioblastoma cell lines. (a) Cell lysates of established glioblastoma cell lines A172, T98G, U373, and Ln229 as well as primary glioblastoma cells WKI and LKI and Jurkat T-lymphoma cells were separated by gel electrophoresis. Protein levels of the antiapoptotic Mcl-1, Bcl-2, Bcl-xL, and the pro-apoptotic Bax, Bak, Noxa, Puma, Bim, and Bad were analyzed by western blot. In addition, protein levels of the Mcl-1-stabilizing deubiquitinase USP $9 \mathrm{x}$ were determined in all cell lines. $\beta$-actin was used as loading control. Mcl-1 and USP9x protein levels were higher in glioblastoma cells than in Jurkat T-lymphoma cells. (b) Densitometric analysis of USP9x and Mcl-1 was performed. Protein levels of Mcl-1 (upper panel) and USP9x (lower panel) were normalized to $\beta$-actin and then to these of Jurkat T cells. Results show mean values \pm S.D. $(n=3)$. No significant regulation was observed

the amount of $A 172$ cells with fragmented DNA and to lesser extent of Ln229 cells, whereas it hardly induced DNA fragmentation in U373 and T98G cells (Figure 5b). In contrast, Mcl-1 knockdown resulted in significantly increased DNA fragmentation in all four cell lines (Figure $5 \mathrm{c}$ ).

Effect of USP9x and Mcl-1 knockdown on irradiated glioblastoma cells. We previously described a radiosensitizing effect of USP9x in Jurkat cells. ${ }^{9}$ Therefore, we examined the influence of Mcl-1 and USP9x knockdown on apoptosis induction in glioblastoma cells following irradiation with 10 Gy by flow cytometry analyzing DNA fragmentation and $\Delta \Psi \mathrm{m}$ dissipation.

Downregulation of $\mathrm{MCl}-1$ significantly increased IR-induced DNA fragmentation in A172, Ln229, and T98G cells, but had no effect in U373 cells (Figure 6a). Successful Mcl-1 knockdown in glioblastoma cells was verified by western blot (Figure $6 \mathrm{~b}$ ). IR-induced $\Delta \Psi \mathrm{m}$ dissipation was increased in all four cell lines transfected with Mcl-1 siRNA (Supplementary Figure S6A). The data suggest that lowered Mcl-1 levels could sensitize the glioblastoma cells to IR-induced apoptosis or, in case of U373 cells, accelerate IR-induced apoptosis.

In A172 cells, downregulation of USP9x by siRNA already resulted in intense DNA fragmentation that was insignificantly increased after irradiation (Figure 6c). A significant increase of IR-induced DNA fragmentation was observed in Ln229 cells transfected with USP9x siRNA. In contrast, no effect of USP9x knockdown on IR-induced DNA fragmentation was observed in U373 and T98G cells. Similar effects were observed by analyzing $\Delta \psi m$ dissipation (Supplementary Figure S6B). The data show that USP9x knockdown could sensitize Ln229 cells to IR-induced apoptosis or accelerate IR-induced apoptosis as in U373 cells, but had no effect in other glioblastoma cell lines.

Following transfection with USP9x siRNA and irradiation, we observed a strong downregulation of $\mathrm{Mcl}-1$ in nonirradiated $A 172$ cells, which was even stronger after irradiation (Figure 6d). In contrast, IR resulted in decreased Mcl-1 levels in U373 and T98G cells, but the Mcl-1 protein level was not affected by USP9x knockdown. In Ln229 cells, neither USP9x siRNA nor irradiation had any effect on Mcl-1.

Taken together, downregulation of $\mathrm{Mcl}-1$ could sensitize glioblastoma cells to or accelerate IR-induced apoptosis. In contrast, downregulation of USP9x had a strong effect on cell survival in A172 cells but showed a sensitizing effect to IRinduced apoptosis only in Ln229 cells without affecting Mcl-1 levels.

Irradiation and Mcl-1 knockdown sensitized glioblastoma cells to $\mathrm{Bcl}-2 / \mathrm{Bcl}-\mathrm{xL}$-induced apoptosis. Maintaining high Mcl-1 levels seemed to be important for all glioblastoma cells. However, all antiapoptotic Bcl-2 family members need to be neutralized to successfully induce apoptosis. To analyze the role of other antiapoptotic $\mathrm{Bcl}-2$ family members in the control of cell survival, we treated A172, U373, Ln299, and T98G cells with different concentrations of the $\mathrm{Bcl}-2 / \mathrm{Bcl}-\mathrm{xL}$ inhibitor ABT737 and with radiotherapy. Apoptosis was assessed by flow cytometry analyzing DNA fragmentation (Figure 7a) and $\Delta \psi \mathrm{m}$ dissipation (Supplementary Figure S7A). Our results show that U373 and T98G cells reacted more susceptible to ABT737 than A172 and Ln229 cells. However, combined with radiotherapy, ABT737 increased apoptosis in all four glioblastoma cell lines. Moreover, our data show that irradiated cells that downregulate $\mathrm{Mcl}-1$ levels respond better 

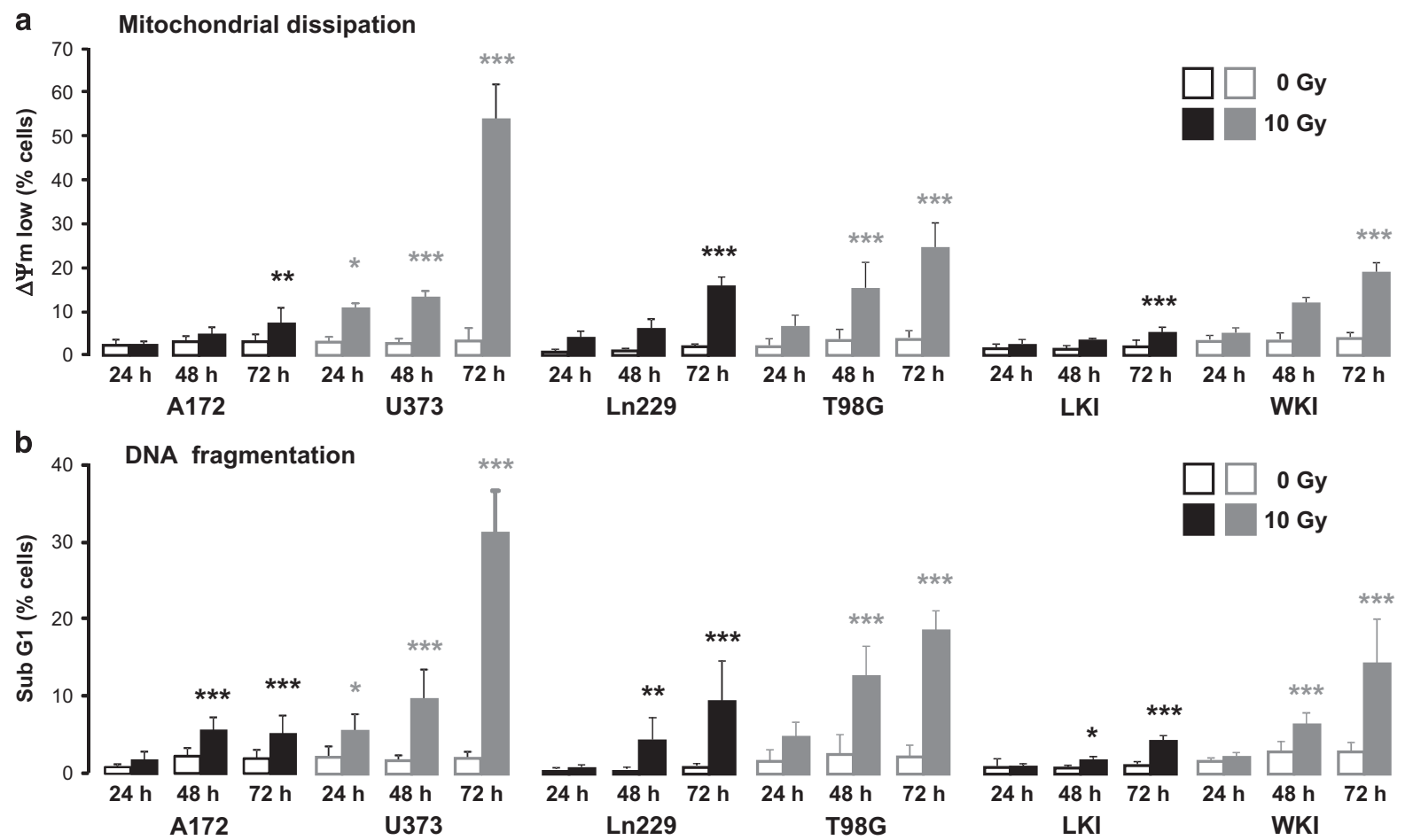

C

A172

U373

Ln229

T98G

LKI

WKI
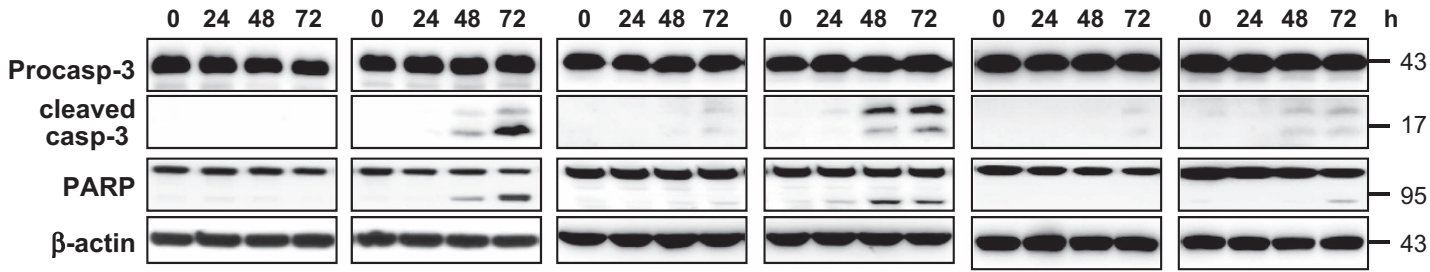

d

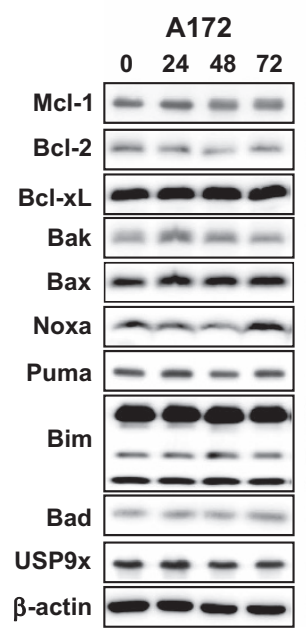

U373

Ln229

T98G

LKI

WKI
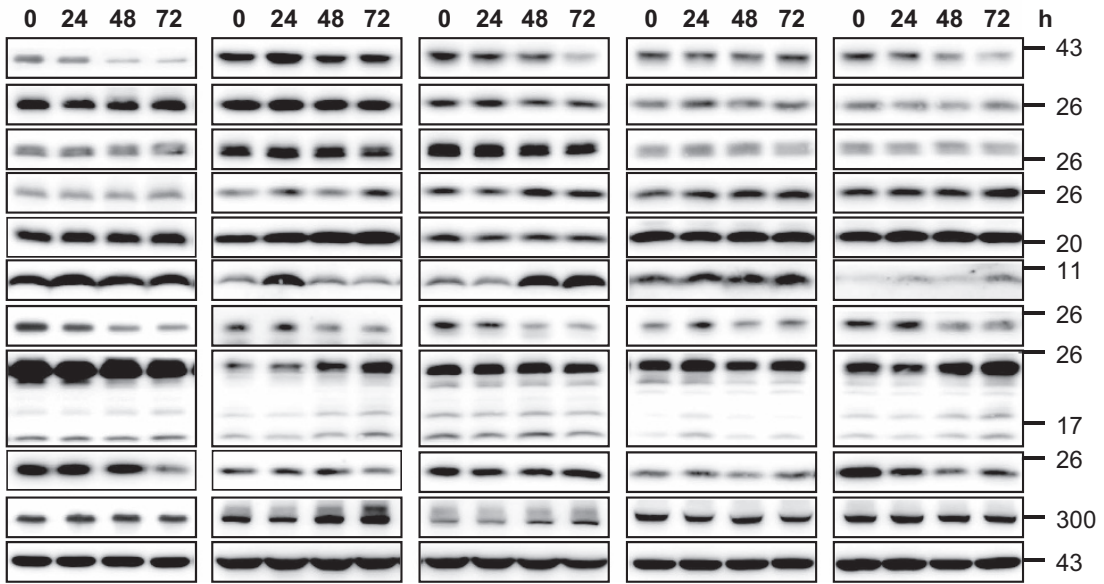

Figure 3 lonizing radiation induced downregulation of Mcl-1 and caspase-dependent apoptosis in U373, T98G, and WKI cells. A172, U373, Ln229, T98G, LKI, and WKI glioblastoma cells were irradiated with 0 Gy or 10 Gy. $24 \mathrm{~h}, 48 \mathrm{~h}$, and $72 \mathrm{~h}$ after irradiation, dissipation of mitochondrial membrane potential ( $\Delta$ Ym low, a) and DNA fragmentation (sub G1, b) were analyzed by flow cytometry. $72 \mathrm{~h}$ after irradiation, dissipation of $\triangle \Psi \mathrm{m}$ and DNA fragmentation were clearly increased in U373, T98G, and, to a lesser extent, in WKI cells. Flow cytometric data show mean values \pm S.D. $(n \geq 6)$. Significance was calculated to the respective non-irradiated control cells. ${ }^{*} P<0.05,{ }^{* \star} P<0.01,{ }^{* \star *} P<0.001$. (c, d) $0-72 \mathrm{~h}$ after irradiating glioblastoma cells, lysates were made and analyzed by western blot. $\beta$-actin was used as loading control. (c) Caspase-3 and PARP cleavage were detected only in U373, T98G, and WKI cells 48 and $72 \mathrm{~h}$ after irradiation, indicating apoptosis induction in response to IR in these cells but not in A172, Ln229, and LKI cells. (d) Protein levels of antiapoptotic Mcl-1 were downregulated in U373, T98G, and WKI cells 48 and $72 \mathrm{~h}$ after irradiation. The Mcl-1 decay correlated with cpase-3 and PARP cleavage. No change of antiapoptotic Bcl-2 and Bcl-xL levels was observed upon irradiation. The regulation of the pro-apoptotic proteins in response to IR differed between the cell lines, but it did not correlate with apoptosis induction 
a

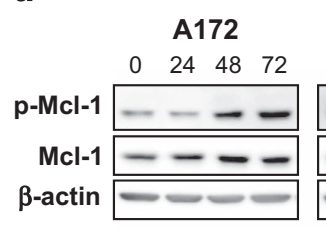

b

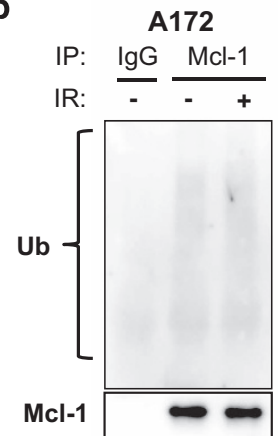

C

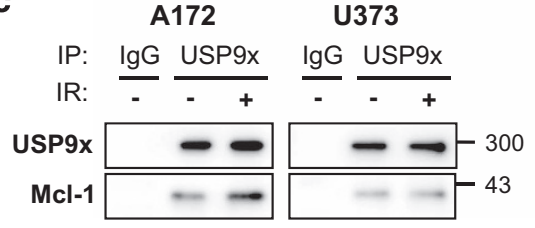

U373

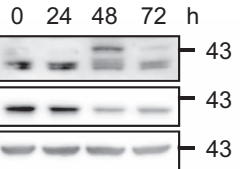

U373
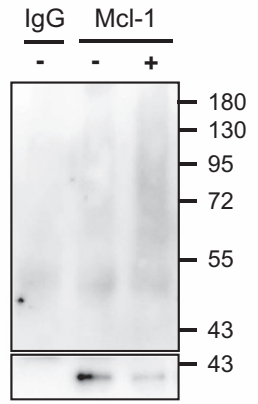

U373
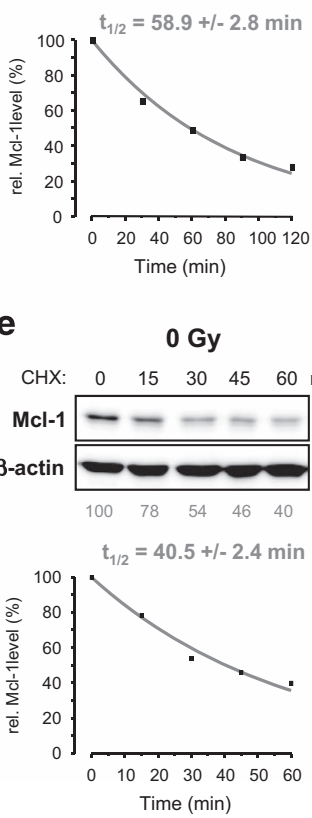

Time (min)

e
0 Gy
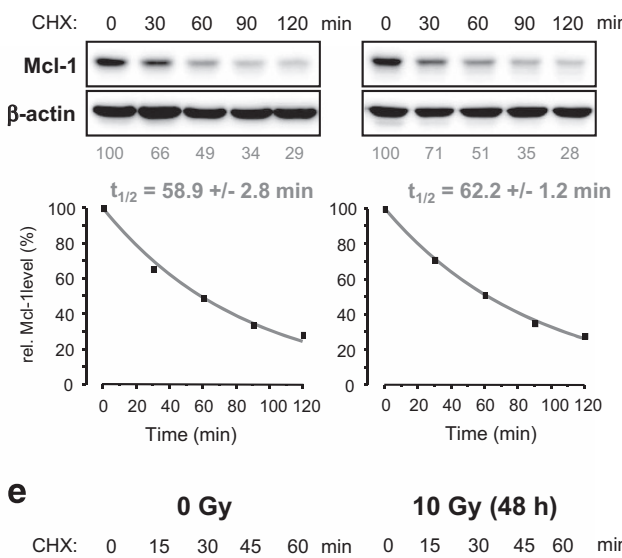

$10 \mathrm{~Gy}(48 \mathrm{~h})$
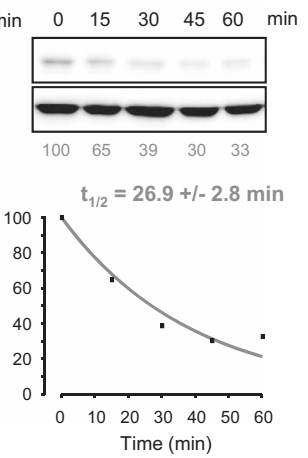
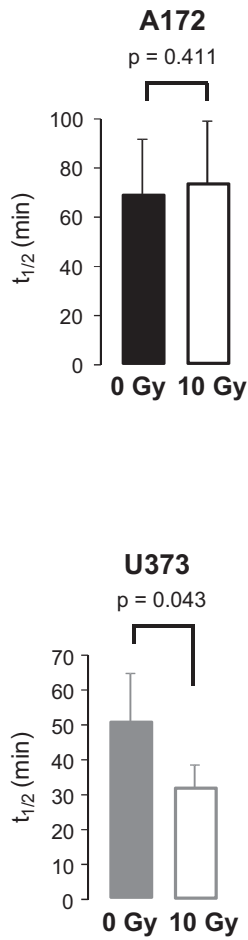

Figure 4 Mcl-1 stability decreased in U373 but not in A172 cells following irradiation. (a) 0-72 h after irradiating A712 and U373 cells with 10 Gy, lysates were made. Phospho (S163)-Mcl-1 and total Mcl-1 were analyzed by western blot. $\beta$-actin was used as loading control. A shift of phosphorylated Mcl-1 was observed in U373 cells $48-72 \mathrm{~h}$ after irradiation, indicating post-translational modification of Mcl-1. (b, c) $48 \mathrm{~h}$ after irradiating A172 and U373 cells with 0 or 10 Gy (IR:- or +), lysates were made. (b) Mcl-1 was precipitated (IP: Mcl-1), and the ubiquitylation status of Mcl-1 was analyzed by western blot. (c) USP9x was precipitated (IP: USP9x), and USP9x as well as co-precipitated Mcl-1 were analyzed by western blot. As a control, precipitation experiments were performed with unspecific isotype-matched immunoglobulins (IP: IgG) and lysates from non-irradiated cells. Ubiquitylated Mcl-1 was increased $48 \mathrm{~h}$ after IR in U373 but not in A172 cells. At the same time, more Mcl-1 precipitated with USP9x in A172 cells after irradiation, whereas the association was not changed in U373 cells. Precipitation experiments were performed twice. After $48 \mathrm{~h}$ of irradiation with 0 Gy or $10 \mathrm{~Gy}, \mathrm{~A} 172$ (d) and U373 (e) cells were treated with $5 \mu \mathrm{M}$ cycloheximide (CHX) for the indicated time (upper panels). Cells were lysed at respective time points, and Mcl- 1 levels were analyzed by western blot. $\beta$-actin was used as loading control. After densitometric quantification, values were normalized to the respective loading control ( $\beta$-actin) and then to the respective untreated control values. The results of the densitometric analysis are shown below the blots (lower panels). Subsequently, Mcl-1 values were fitted and the half-life of Mcl-1 was calculated (right panels). Bar diagrams show the average half-life time of Mcl-1 in non-irradiated and irradiated cells \pm S.D. $(n=3)$. Mcl-1 stability remained unchanged in A172 cells but was significantly decreased in U373 cells $48 \mathrm{~h}$ after irradiation

to $\mathrm{Bcl}-2 / \mathrm{Bcl}-\mathrm{xL}$ inhibition than irradiated cells that fail to downregulate Mcl-1. To confirm this observation described above, we knocked down Mcl-1 by siRNA before treating the cells with ABT737 (Figure 7b, Supplementary Figure S7B). As expected, Mcl-1 knockdown sensitized all four glioblastoma cell lines to ABT737-induced apoptosis. Apoptosis induction by $\mathrm{Bcl}-2 / \mathrm{Bcl}-\mathrm{xL}$ inhibition was as effective in $\mathrm{A} 172$ and Ln229 cells as in U373 and T98G cells. These results confirm the importance of $\mathrm{Mcl}-1$ in regulation of survival.

USP9x knockdown increased sensitivity to IR in A172 and Ln229 cells. After measuring the influence of USP9x on irradiated glioblastoma cells in a short-term assay, we analyzed the influence of USP9x on long-term survival by a colony-formation assay measuring the clonogenic survival upon transfection with USP9x siRNA or the non-targeting control siRNA and irradiation (Figure 8). After irradiation, the surviving fraction (SF) was decreased in all four glioblastoma cell lines in a dose-dependent manner. USP9x knockdown further reduced SF in A172 and Ln229 cells. In contrast,
USP9x did not affect radiosensitivity in U373 and T98G cells. Our data show that USP9x regulates radiosensitivity only in some glioblastoma cells.

\section{Discussion}

Patients with glioblastoma usually undergo neurosurgical tumor removal before adjuvant radiotherapy, usually combined with temozolomide.$^{13}$ However, many patients do not respond or respond only partially to IR. Novel strategies are needed to improve the response to radiochemotherapy. One therapeutic option might be the targeting of the antiapoptotic $\mathrm{Bcl}-2$ family members that control intrinsic apoptosis.

Here, we used four established glioblastoma cell lines and two primary glioblastoma cell lines that express the antiapoptotic proteins $\mathrm{Bcl}-2, \mathrm{Bcl}-\mathrm{xL}$, and $\mathrm{Mcl}-1$, but showed different sensitivity to IR-induced apoptosis. In contrast to the A172, Ln229 and LKI cells, the cell lines U373, T98G, and WKI downregulated Mcl-1 and induced caspase-dependent apoptosis in response to IR. The decline of Mcl-1 levels upon 


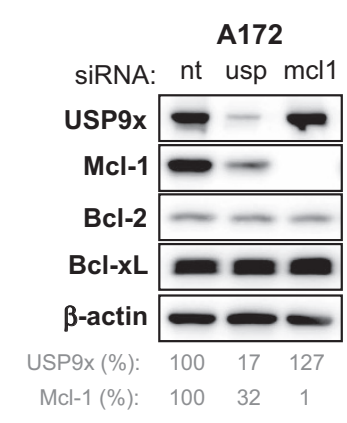

b

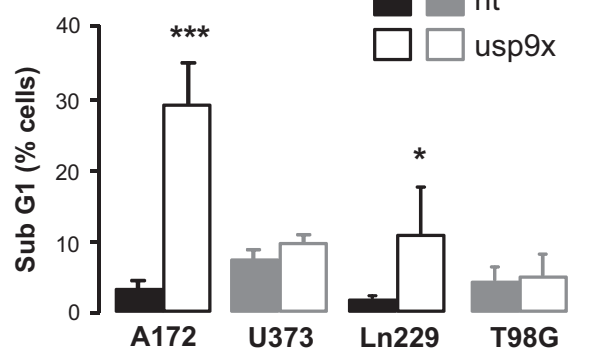

U373

nt usp mcl1

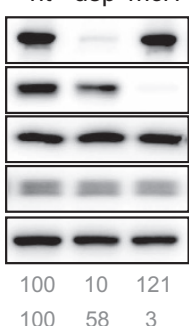

Ln229

nt usp mcl1 nt usp mcl1

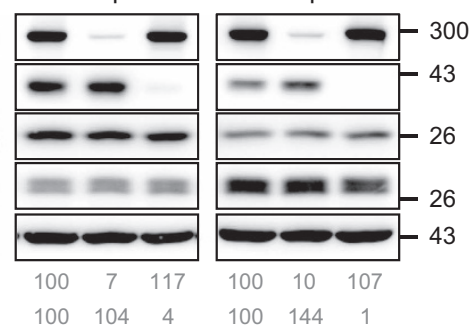

c

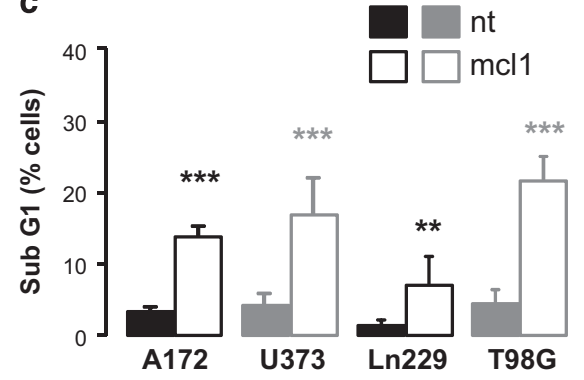

Figure 5 Downregulation of Mcl-1 induced apoptosis in all glioblastoma cells, whereas downregulation of USP9x induced apoptosis only in IR-resistant A172 and Ln229 cells. (a, b) A172, U373, Ln229, and T98G cells were transfected with $100 \mathrm{nM}$ siRNA targeting USP9x (usp) or $50 \mathrm{nM}$ siRNA-targeting Mcl-1 (mcl1). Control transfection was performed with respective amount of non-targeting (nt) siRNA. (a) After $72 \mathrm{~h}$ of transfection, protein levels of USP9x, Mcl-1, Bcl-2, and Bcl-xL were analyzed by western blot. $\beta$-actin was used as loading control. After densitometric analysis, USP9x and Mcl-1 protein levels were normalized to the respective loading control followed by normalization to respective protein levels in cells transfected with nt siRNA. USP9x knockdown decreased Mcl-1 protein levels clearly in A172 and slightly in U373 cells. After $72 \mathrm{~h}$ of transfection with USP9x siRNA (b), Mcl-1 siRNA (c), or the respective amount of nt siRNA, DNA fragmentation was analyzed by flow cytometry. USP9x knockdown resulted in significant apoptosis induction in A172 and Ln229 cells only (b), whereas Mcl-1 knockdown significantly induced apoptosis in all glioblastoma cell lines. (c) Flow cytometric data show mean values \pm S.D. (A172, U373: $n=3$; Ln229: $n=5$; T98G: $n=10$ ). Significance was calculated to the respective cells transfected with non-targeting siRNA. ${ }^{*} P<0.05,{ }^{* *} P<0.01$, ${ }^{* * *} P<0.001$

irradiation have been correlated before with apoptosis induction in Jurkat T-lymphoma cells. ${ }^{9}$ In addition, Mcl-1 increased resistance of glioblastoma cells to apoptosis induced by temozolomide or the death ligand TRAIL. ${ }^{17,18}$ Thus, the failure to downregulate Mcl-1 levels in A172, Ln229, and LKI cells could be responsible for survival after irradiation.

Regulation of Mcl-1 stability in glioblastoma cells. Mcl-1 levels are regulated at the transcriptional and translational level. 8 Moreover, $\mathrm{Mcl}-1$ stability is controlled by post-translational modifications. Usually, Mcl-1 is quickly ubiquitylated and subsequently degraded by proteasomes. Until now, three ubiquitin ligases have been described that catalyze the ubiquitylation of $\mathrm{Mcl}-1,{ }^{11,20-22}$ whereas the deubiquitinase USP9x is able to antagonize this reaction by removing the polyubiquitin chains, thereby stabilizing Mcl-1. ${ }^{9,21}$ In addition, phosphorylation of Mcl-1 by GSK-3 $\beta$ can accelerate $\mathrm{Mcl}-1$ ubiquitylation and degradation. ${ }^{10}$ Our results show that phosphorylated $\mathrm{Mcl}-1$ was more ubiquitylated, whereas Mcl-1 half-life time was reduced in U373 cells after irradiation. Neither Mcl-1 ubiquitylation nor $\mathrm{Mcl}-1$ stability were affected in A172 cells in response to irradiation. The data suggest that, in U373 cells, ubiquitylation targeted Mcl-1 for proteasomal degradation in response to IR, whereas phosphorylated $\mathrm{Mcl}-1$ was stabilized in irradiated A172 cells. As the interaction between $\mathrm{Mcl}-1$ and the deubiquitinase USP9x was not changed in U373 cells upon irradiation, we think that the increased $\mathrm{Mcl}-1$ polyubiquitylation was due to enhanced ubiquitylation activity rather than to reduced USP9x activity. Alternatively, the activity of another, not yet identified, deubiquitinase regulating Mcl-1 stability in U373 cells could be compromised in U373 cells upon irradiation. Ku70, a component of the nonhomologs end joining DNA repair pathway, was recently shown to interact with and deubiquitylate Mcl-1, thereby linking DNA repair to apoptosis. ${ }^{23}$ Whether the activity of Mcl1-specific ubiquitin ligases is increased or the Ku70 deubiquitylating activity is reduced after IR in apoptosisinducing glioblastoma cells, this needs further investigation. On the other hand, the increased interaction between $\mathrm{Mcl}-1$ and USP9x in irradiated A172 cells implicates that USP9x contributes to $\mathrm{Mcl}-1$ stabilization, thereby improving survival following irradiation in this cell line.

USP9x is a potential radiosensitizing factor. Low USP9x levels have been correlated with low Mcl-1 levels and increased susceptibility to IR. ${ }^{12}$ Thus, knockdown of USP9x might result in cell death when cell survival depends on high Mcl-1 levels. In A172, downregulation of USP9x by siRNA resulted in lowered $\mathrm{Mcl}-1$ levels and massive apoptosis induction. Irradiation only slightly increased cell death, whereas it further decreased Mcl-1 levels. Nevertheless, USP9x knockdown had a remarkable radiosensitizing effect in colony-formation assay. A radiosensitizing effect was also observed in Ln229 cells after transfection with USP9x siRNA. In this cell line, downregulation of USP9x resulted in 
a

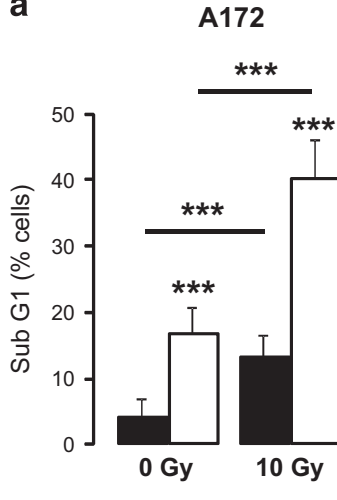

U373

b

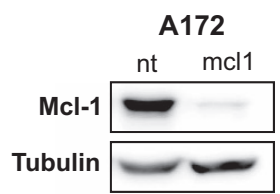

C

A172

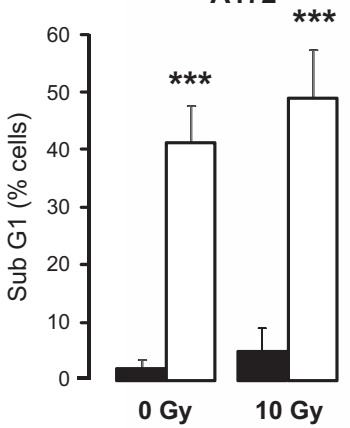

U373

U373

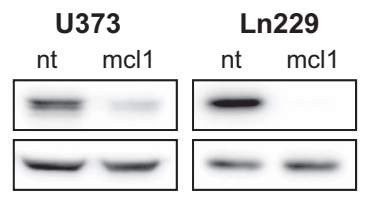

Ln229

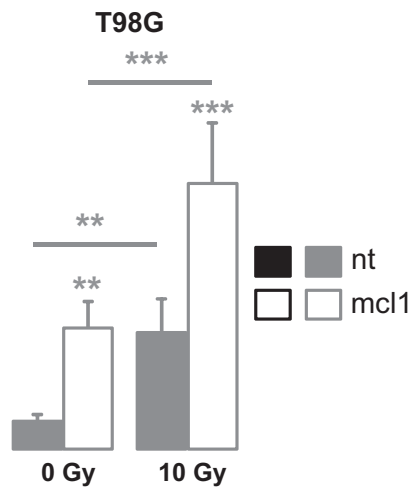

T98G

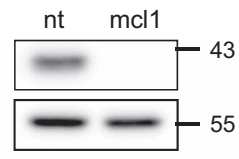

Ln229

T98G

d

A172
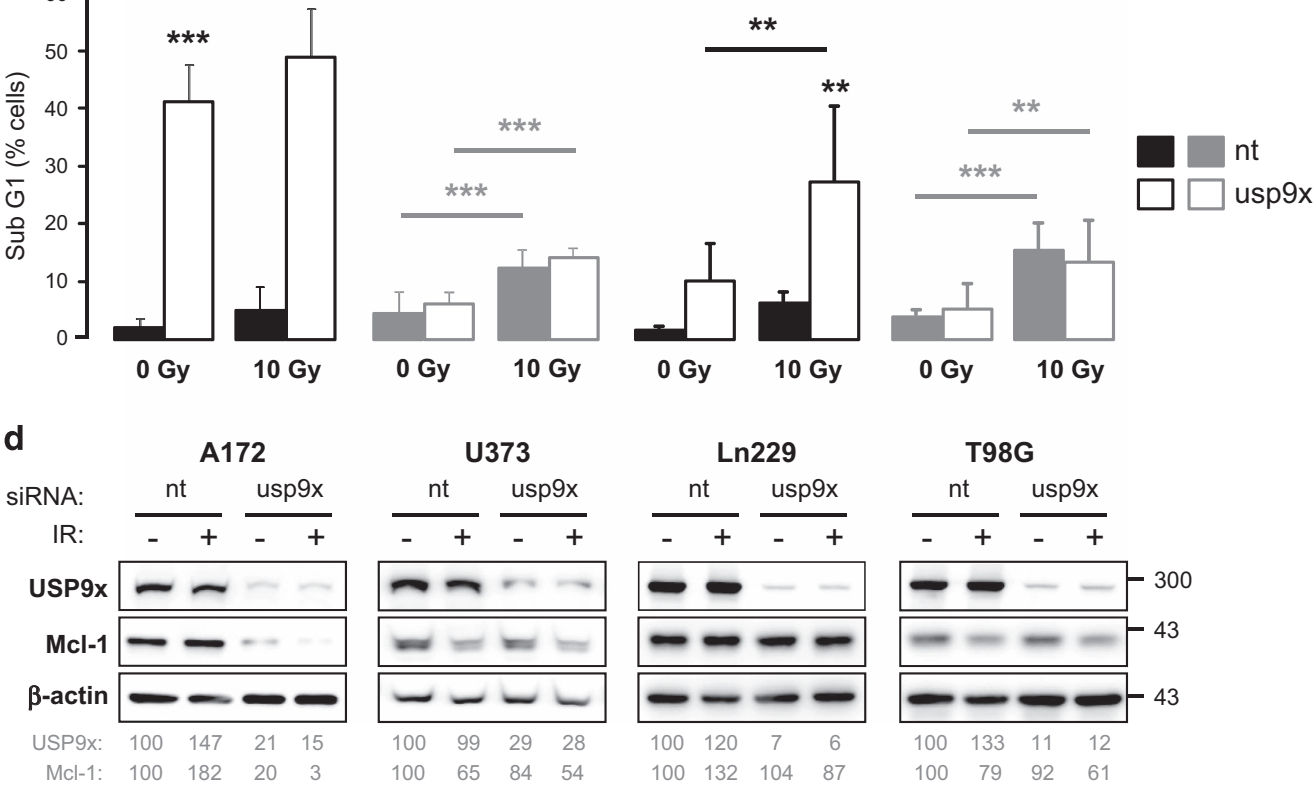

U373
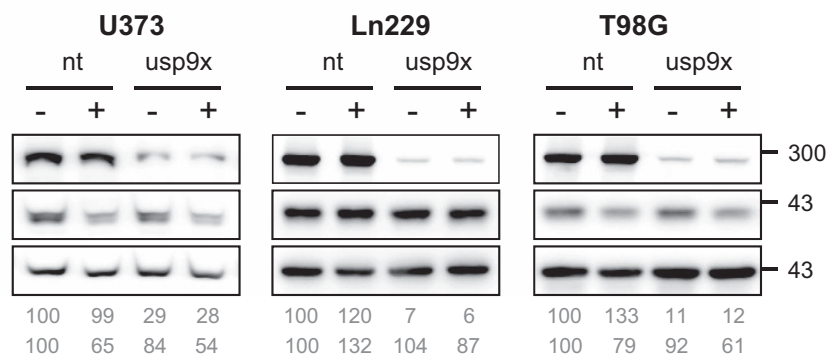

Figure 6 Effects of Mcl-1 and USP9x knockdown on IR-induced apoptosis in glioblastoma cells. (a-d) A172, U373, Ln229, and T98G cells were transfected with 50 nM siRNA targeting Mcl-1 (mcl1), $100 \mathrm{nM}$ siRNA targeting USP9x (usp9x), or with the respective amount of non-targeting (nt) siRNA. After $48 \mathrm{~h}$, cells were irradiated with 0 Gy or 10 Gy. (a) 48 h after irradiation, DNA fragmentation was analyzed by flow cytometry after Mcl-1 knockdown. Data shows mean values \pm S.D. (A172, U373: $n=6$; A172, Ln229, T98G: $n=5$ ). (b) Mcl-1 knockdown was verified by western blot $48 \mathrm{~h}$ after transfection. Mcl-1 knockdown significantly increased IR-induced DNA fragmentation in A172, Ln229. and T98G cells. (c) After $48 \mathrm{~h}$ of irradiation, DNA fragmentation was analyzed by flow cytometry after USP9x knockdown. Data show mean values \pm S.D. (A172: $n=6$; U373: $n=9$; Ln229, T98G: $n=5$ ). (b) USP9x and Mcl-1 protein levels were analyzed by western blot. $\beta$-actin was used as loading control. After densitometric analysis, USP9x and Mcl1 levels were normalized to respective $\beta$-actin levels and then to non-irradiated cell transfected with nt siRNA. USP9x knockdown slightly enhanced IR-induced downregulation of Mcl-1 levels and apoptosis induction in A172 cells, whereas, in Ln229 cells, IR-induced apoptosis was significantly increased without affecting Mcl-1 levels. Significance in a and c was calculated to the respective cells transfected with nt siRNA and, where indicated by a line, to non-irradiated control cells. ${ }^{\star} P<0.05,{ }^{\star \star} P<0.01,{ }^{\star \star \star} P<0.001$

increased apoptosis and reduced clonogenic survival. However, Mcl-1 protein levels were neither affected by USP9x nor by IR, suggesting that USP9x increased resistance to IR-induced apoptosis and clonogenic cell death independently of Mcl-1. In contrast, USP9x had no radiosensitizing effect in U373 and T98G cells, although
USP9x knockdown accelerated IR-induced apoptosis in U373 cells.

USP9x has also been shown to positively regulate brain tumor growth. ${ }^{24}$ We detected a significantly higher USP9x expression in glioblastoma than in astrocytoma. Thus, our data indicate that USP9x has a role during tumor progression 
a
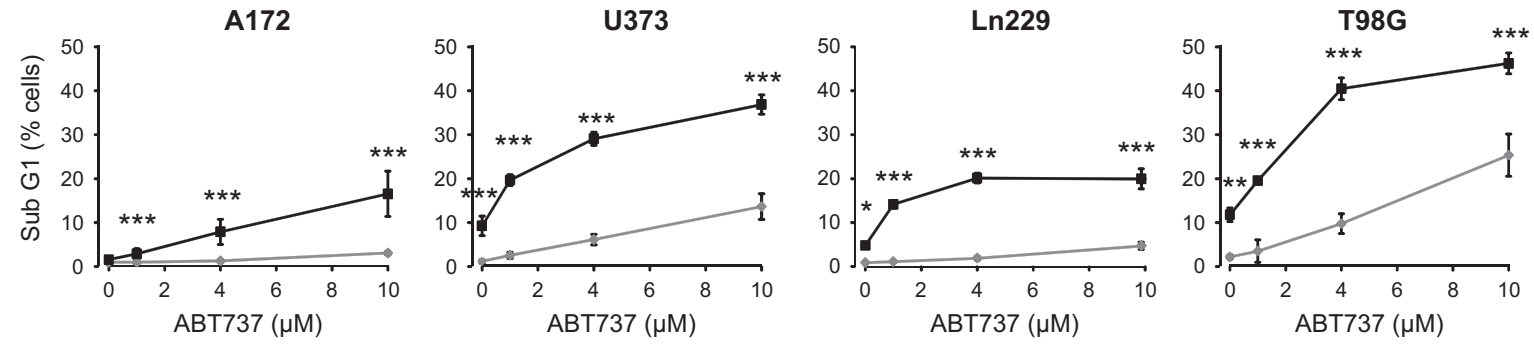

b
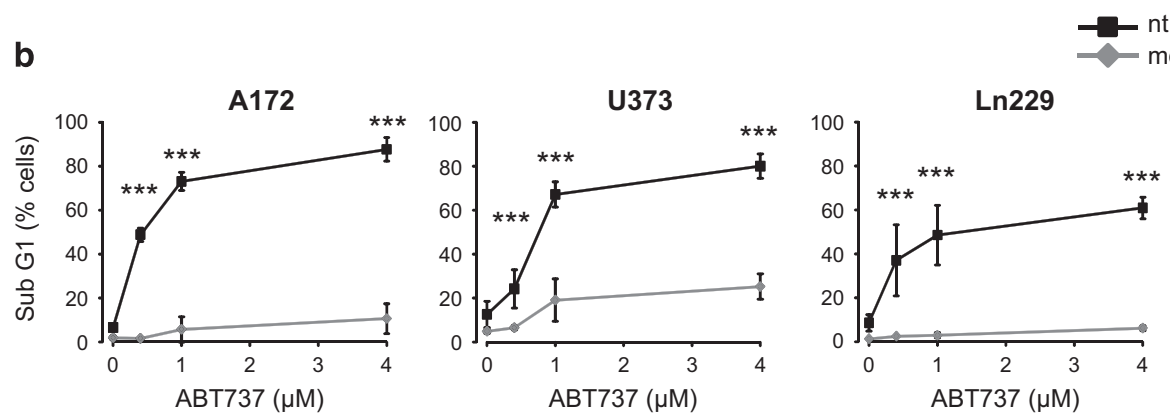

t siRNA

mcl1 siRNA

Figure 7 Inhibition of Bcl-2 and Bcl-xL improved apoptosis induction in response to irradiation and downregulation of Mcl-1. (a) A172, U373, Ln229, and T98G cells were irradiated (0 Gy, $10 \mathrm{~Gy})$ and treated with the Bcl-2/Bcl-xL inhibitor ABT737 $(0 \mu \mathrm{M} /$ solvent control, 1, 4, or $10 \mu \mathrm{M})$ immediately after irradiation. DNA fragmentation was analyzed $48 \mathrm{~h}$ after irradiation and treatment. IR increased ABT737-induced apoptosis in all glioblastoma cells, but to a greater extent in U373 and T98G than in A172 and Ln229 cells. Flow cytometric data show mean values \pm S.D. (A172, U373: $n=6$; Ln229, T98G: $n=3$ ). (b) A172, U373, Ln229, and T98G cells were transfected with $50 \mathrm{nM} \mathrm{Mcl-1}$ (mcl1) siRNA or the respective non-targeting (nt) siRNA. After $24 \mathrm{~h}$ of transfection, cells were treated with ABT737 ( $0 \mu \mathrm{M} /$ solvent control, $0.4,1$, or $4 \mu \mathrm{M})$. After $48 \mathrm{~h}$, DNA fragmentation was analyzed by flow cytometry. Mcl-1 knockdown facilitates ABT737-induced apoptosis in A172 and Ln229 cells to a similar extent as in U373 and T98G cells. Flow cytometric data show mean values \pm S.D. $(n=3)$. Significance was calculated to the respective non-irradiated cells. ${ }^{\star} P<0.05,{ }^{* \star} P<0.01,{ }^{* \star *} P<0.001$

from astrocytoma to glioblastoma. USP9x expression correlated moderately but significantly with $\mathrm{Mcl}-1$ expression in glioblastoma, supporting our hypothesis that USP9x stabilizes Mcl-1 in glioblastoma cells. However, not all glioblastoma tissue samples expressing high $\mathrm{Mcl}-1$ levels also express high USP9x levels. This again implicates that other factors are also important regulators of Mcl-1 levels in glioblastoma tumors.

Further publications point to a multifaceted role of USP9x in the brain. ${ }^{25,26}$ The diverse effects of USP9x could be signaled through different proteins targeted by USP9x. In addition to Mcl-1, USP9x also stabilizes $\beta$-Catenin and ubiquitin ligase Itch. ${ }^{27,28}$ High $\beta$-catenin levels were correlated with increased radioresistance in pancreatic cancer cells, ${ }^{29}$ whereas Itch regulates the internalization of epidermal growth factor receptor, a growth receptor that mediates radioresistance in glioblastoma tumors. ${ }^{30,31}$ Moreover, stabilization of Foxo3A by USP9x resulted in decreased cyclin D1 levels and cell cycle arrest. $^{32}$ Although the three USP9x interaction partners have not been examined in our glioblastoma cells, it is possible that USP9x modulates the response to IR in Ln229 and A172 cells through these and other effector proteins.

Dependency on $\mathrm{Bcl}-2 / \mathrm{Bcl}-\mathbf{x L}$. The antiapoptotic family members $\mathrm{Bcl}-2, \mathrm{Bcl}-\mathrm{xL}$, and $\mathrm{Mcl}-1$ are often overexpressed in glioblastoma. $^{33}$ Successful targeting of the protective proteins alone or in combination with other therapies has been repeatedly described. ${ }^{5,14,34-36}$ Generally, the more antiapoptotic proteins can be neutralized, the better is apoptosis induction. Among the best described inhibitors targeting antiapoptotic Bcl-2 family members is the Bad-mimicking compound ABT737 and its orally available analog ABT263, both of which were shown to inhibit Bcl-2 and Bcl-xL. ${ }^{7,37}$ We have shown that A172 and Ln229 cells that hardly induced apoptosis after irradiation were also very resistant to ABT737-induced apoptosis, whereas U373 and T98G cells that induced apoptosis after irradiation reacted more sensitively to $\mathrm{Bcl}-2 / \mathrm{Bcl}-\mathrm{xL}$ inhibition. The differences between the cell lines could be explained by different capacity to sequester pro-apoptotic Bcl-2 family members. Mcl-1 contributes to the neutralizing capacity, as downregulation of Mcl-1 sensitized all four glioblastoma cells to ABT737induced apoptosis.

Interestingly, all cell lines could also be sensitized to ABT737-induced apoptosis by irradiation, suggesting additional sensitizing events by IR. Following irradiation, an upregulation of pro-apoptotic Bax was observed in Ln229 cells, whereas $\mathrm{BH} 3-o n l y$ protein Bim levels were increased in Ln229 and WKI cells in response to IR. Moreover, irradiation increased Noxa levels especially in T98G and WKI cells. Bim can antagonize all three antiapoptotic proteins and directly activate Bax and Bak. ${ }^{38}$ Noxa was described to specifically antagonize $\mathrm{Mcl}-1$ but not $\mathrm{Bcl}-2$ and $\mathrm{Bcl}-\mathrm{xL}^{38}$ In addition, a recent publication showed that Noxa is also able to directly activate Bax and Bak. ${ }^{39}$ All three proteins can shift the balance between anti- and pro-apoptotic Bcl-2 family members toward cell death. Interestingly, Bax and Noxa can be transcriptionally upregulated by $\mathrm{p} 53$, a tumor suppressor that is upregulated in response to IR. ${ }^{40-42}$ Alterations of p53 are commonly 

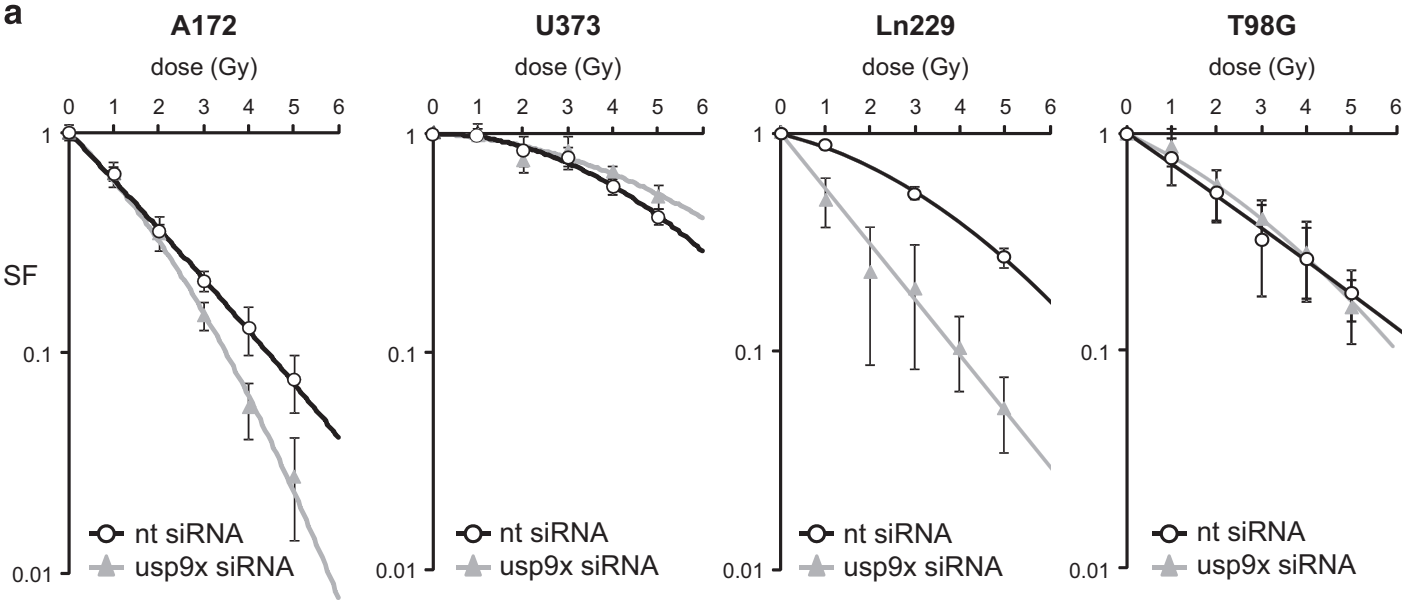

b

A172

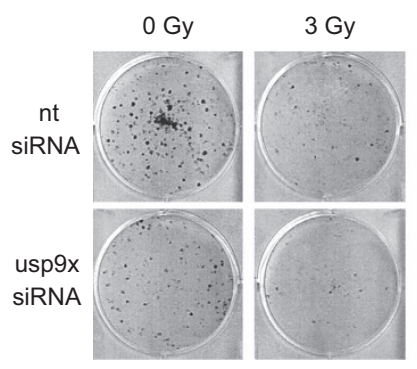

U373
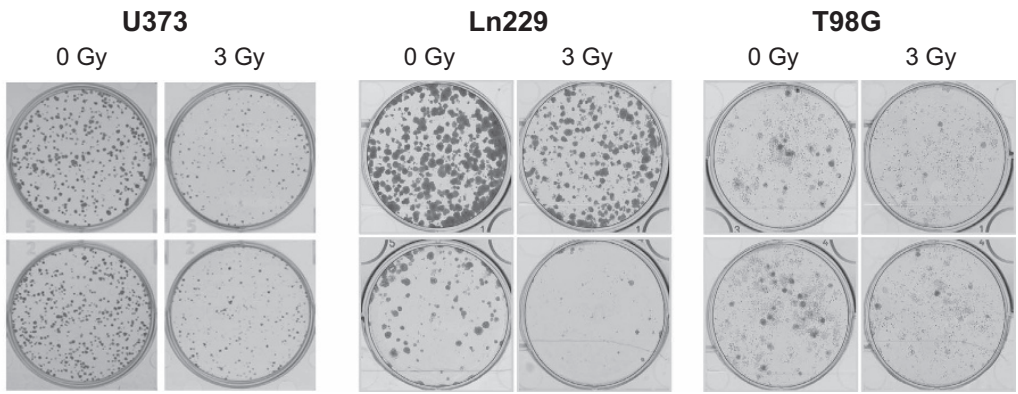

Figure 8 Downregulation of USP9x by siRNA increased clonogenic death of irradiated A172 and Ln229 cells. In total, 3000 cells were seeded per well and transfected with $100 \mathrm{nM}$ siRNA-targeting USP9x (usp9x) or non-targeting (nt) siRNA $24 \mathrm{~h}$ later. After $48 \mathrm{~h}$ of transfection, A172 and U373 cells were irradiated with 0-5 Gy. Colonies were allowed to form for 8-10 days. After counting the colonies, the surviving fraction (SF) was calculated. Surviving curves in response to IR are shown in (a), whereas representative wells are shown in (b). USP9x knockdown decreased the respective surviving fractions and, thus, increased clonogenic cell death in A172 and Ln229 cells, but showed no significant effect in U373 cells. Data show mean SF values \pm S.D. of one experiment that was performed in triplicates. One representative experiment of two is shown

observed in glioblastoma. ${ }^{43}$ We found that $\mathrm{p} 53$ levels were already elevated in non-irradiated T98G, U373, and WKI cells, suggesting that p53 was mutated in these cell lines (Supplementary Figure S2). Moreover, none of the other glioblastoma cell lines induced p53 after irradiation, implicating an impaired p53 response following irradiation, thus, excluding any p53-dependent regulation of pro-apoptotic Bcl-2 family members.

Taken together, downregulation of Mcl- 1 in response to IR is an important step in IR-induced apoptosis in glioblastoma cells. Furthermore, USP9x can act as a radioprotective protein either by maintaining high $\mathrm{Mcl}-1$ levels or by regulating alternative mechanisms.

\footnotetext{
Material and Methods

Reagents and antibodies. Cycloheximide was purchased from Sigma (Deisenhofen, Germany). ABT737 was obtained from Active Biochemicals (Bonn, Germany).

Following antibodies were used for western blotting: rabbit-anti Bak from Upstate (distributed by Millipore, Schwalbach, Germany), rabbit- anti caspase-3, PARP, Mcl-1, Bcl-xL, Bax, Puma, Bim, Tubulin, and mouse anti-Ubiquitin (clone P4D1) from Cell Signaling (distributed by NEB, Frankfurt, Germany), mouse anti-Mcl-1 from Pharmingen and mouse anti-Bad from Transduction Laboratories (distributed by Becton Dickinson, Heidelberg, Germany), mouse-anti Bcl-2 from Santa Cruz Biotechnology (Heidelberg, Germany), mouse anti-Noxa from Calbiochem (distributed by Merck, Darmstadt, Germany), rabbit-anti-USP9x from Novus
}

Biologicals (distributed by Acris, Herford, Germany), and mouse-anti $\beta$-actin was obtained from Sigma.

Cells and cell culture. A172, Ln229, U373, and T98G glioblastoma cell lines as well as Jurkat T-lymphoma cells were from ATCC (Bethesda, MA, USA). According to ATCC, U373 cells used in the present work show genetic similarities to U251 glioblastoma cells. LKI cells were established from primary glioblastoma and provided by the Department of Radiation Oncology, University of Tuebingen, Germany, with patient's consent and approved by the local ethic committee (579/2015BO2), whereas WKI cells were provided by Dr. Mike Fay from Genesis CancerCare (New South Wales, Australia). Cells were grown in RPMl 1640 medium supplemented with $10 \%$ fetal bovine serum (Gibco Life Technologies, Eggenstein, Germany). Cells were maintained in a humidified incubator at $37^{\circ} \mathrm{C}$ and $5 \% \mathrm{CO}_{2}$.

Cells were irradiated at room temperature with $6 \mathrm{MV}$ photons using a linear accelerator (LINAC SL25 Philips, DA Best, the Netherlands) at a dose rate of 4 Gy/min.

Transfection with siRNA. In total, $3-4 \times 10^{5}$ cells were seeded in $2 \mathrm{ml}$ complete medium (RPMI $1640+10 \%$ fetal bovine serum) in a six-well plate. After $24 \mathrm{~h}$, cells were transfected with 50-100 nM of the respective siRNA using Trans-IT siQuest transfection reagent (Mirus, Madison, WI, USA) according to the manufacturers protocol. Mcl-1 and USP9x ON-TARGET SMARTpools, and siCONTROL NON-TARGETING pool were purchased from Dharmacon (Chicago, IL, USA).

Flow cytometric analysis. The mitochondrial membrane potential $(\Delta \Psi \mathrm{m})$ was analyzed using the $\Delta \Psi$ m-specific dye tetramethylrhodamine ethyl ester (TMRE, Molecular Probes, distributed by Thermo Fisher Scientific, Grand Island, NY, USA). At the indicated time points, cells were stained for $30 \mathrm{~min}$ in PBS containing $25 \mathrm{nM}$ TMRE. To examine DNA fragmentation, cells were incubated with 
PBS containing $0.1 \%$ sodium citrate, $0.1 \%$ Triton $\mathrm{X}-100$, and $10 \mu \mathrm{g} / \mathrm{ml}$ propidium iodide. Cells were detected in fluorescence channel 2 employing a FACS Calibur flow cytometer (Becton Dickinson) and analyzed with the FCS Express 3 software (De Novo Software, Los Angeles, CA, USA). Data show mean values \pm S.D. of at least six independent experiments.

Colony-formation assay. Clonogenic survival was analyzed as described before. ${ }^{44}$ In brief, 3000 cells were seeded in six-well plates and transfected with 100 nM USP9x or non-targeting siRNA the next day. After $24 \mathrm{~h}$ of transfection, cells were irradiated with $0-5$ Gy. The cells were incubated as described above for 6-10 days (depending on the cell line) to allow growth of single colonies. After that, cells were fixed with $3.7 \%$ formaldehyde and $70 \%$ ethanol and subsequently stained with $0.05 \%$ Coomassie Brilliant Blue. Colonies ( $>50$ cells/colony) were counted. To determine the SF, the ratio of colonies counted/seeded cells was calculated and normalized to that of untreated control cells. The fitting of the curves was performed using Excel software. Error bars indicate the mean values \pm S.D. Two independent experiments were performed.

Western blot analysis. Cells were lysed in $200 \mu$ lysis buffer containing $50 \mathrm{mM}$ HEPES pH 7.5, $150 \mathrm{mM} \mathrm{NaCl}, 1 \%$ Triton X-100, $1 \mathrm{mM}$ EDTA, $10 \mathrm{mM}$ sodium pyrophosphate, $10 \mathrm{mM} \mathrm{NaF}, 2 \mathrm{mM} \mathrm{Na} \mathrm{VO}_{4}, 100 \mathrm{mM}$ PMSF, $5 \mu \mathrm{g} / \mathrm{ml}$ Aprotinin, $5 \mu \mathrm{g} / \mathrm{ml}$ Leupeptin, and $3 \mu \mathrm{g} / \mathrm{ml}$ Pepstatin A. Protein was separated by SDS-PAGE under reducing conditions and transferred onto PVDF membranes (Roth, Karlsruhe, Germany). Blots were blocked in TBS buffer containing $0.05 \%$ Tween 20 and $5 \%$ non-fat dry milk for $1 \mathrm{~h}$ at room temperature. The membrane was incubated overnight at $4{ }^{\circ} \mathrm{C}$ with the respective primary antibodies. The secondary antibody was incubated for $1 \mathrm{~h}$ at room temperature. Detection of antibody binding was performed by enhanced chemoluminescence (ECL Western blotting analysis system from GE Healthcare, Freiburg, Germany). Equal loading was verified by antibodies against $\beta$-actin or Tubulin. Where indicated protein levels were quantified by densitometry using ImageJ software (ImageJ $1.40 \mathrm{~g} \mathrm{NIH}$, USA). At least two independent western blot experiments were performed.

Mcl-1 degradation assay. Cells were treated with $2 \mu \mathrm{M}$ cycloheximide for $0-3 \mathrm{~h}$. At indicated time points, cells were lysed, and lysates were separated as described above. Mcl-1 protein levels were detected by western blot. Several blots were made from the same lysates. Protein levels were quantified by densitometry using ImageJ software (ImageJ $1.40 \mathrm{~g} \mathrm{NIH}, \mathrm{USA}$ ) and normalized to the $\beta$-actin levels. After that, Mcl-1 levels were normalized to the initial level $(0 \mathrm{~min}$ cycloheximide). Monoexponential decay was fitted using Origin 6.0 software and included in further analysis when correlation coefficient $R^{2}$ was higher than 0.8 . At least five western blots were analyzed of each experiment and the median was calculated. Three independent experiments were performed.

Immunoprecipitation. Cells were lysed as described above using $1 \%$ CHAPS as detergent. The protein concentration was adjusted to $2 \mathrm{mg} / \mathrm{ml}$. Two micrograms mouse anti-USP9x antibody (H00008239-M01, Abnova, Acris) or five rabbit anti-Mcl-1 (S19, Santa Cruz Biotechnology) and $50 \mu \mathrm{l}$ slurry Dynabeads suspension (Dynal/Invitrogen, Karlsruhe, Germany) were added to $750 \mu$ l lysate. After the precipitation for $3 \mathrm{~h}$ at $4{ }^{\circ} \mathrm{C}$, the beads were washed thrice with $300 \mu \mathrm{l}$ lysis buffer containing $0.2 \%$ of the respective detergent. Proteins were eluted by boiling the beads for $10 \mathrm{~min}$ in $60 \mu \mathrm{l}$ SDS sample buffer containing $2.5 \%$ $\beta$-mercaptoethanol. $30 \mu \mathrm{l}$ of the eluate were separated by SDS gel electrophoresis before transfer to PVDF membrane and detection by chemoluminescence as described above. Precipitations were performed twice in two independent experiments.

Immunohistochemistry. Human tissue samples were obtained from the department of Neurosurgery, University of Tuebingen, with patients' consent approved by the local ethic committee (163/2012B02). Formalin-fixed, paraffinembedded human tumor specimens (astrocytoma WHO grade III, $n=42$; glioblastoma, WHO grade IV, $n=45$ ) were placed on tissue microarrays (TMA two cores, $1000 \mu \mathrm{m}$ each) under supervision of a neuropathologist. TMA blocks were cut to $4 \mathrm{~mm}$ slides and deparaffinized. Immunohistochemical stainings were performed using mouse anti-USP9x from Abnova (H00008239-M01, Acris, $1: 800$ dilution) and rabbit anti-Mcl-1 (S19, Santa Cruz Biotechnology, 1:1600 dilution) antibodies on the automated Benchmark immunohistochemistry system (Ventana Medical Systems, distributed by Roche Diagnostics, Mannheim, Germany). Heat-induced antigen retrieval was performed with $\mathrm{CC} 1$ cell conditioning solution
(Tris-based EDTA buffer, Ventana) for 30 min for USP9x and no pretreatment for Mcl-1. Visualization of the specific antibody binding was achieved using the UltraView Universal DAB kit (Ventana). Human tonsils served as positive controls. Appropriate negative controls (omission of the first antibody) were processed in parallel with each batch of staining.

Staining evaluation: cytoplasmic and nuclear staining were evaluated together. Tumors were considered positive when $>1 \%$ of the tumor cells exhibited a detectable immunoreactivity. The staining intensity was semiquantitatively recorded as absent, weak, moderate, and strong positive. The percentage of stained tumor cells was counted as 0 (negative), $1(1-25 \%), 2(26-50 \%), 3(51-75 \%)$, and $4(76-100 \%)$. Staining intensity score and the score indicating the amount of positive cells were multiplied to obtain the IRS ranging from 0 to 12 . The median \pm S.D. and the 95 percentile were calculated for each grade and each antibody staining. To analyze the correlation between Mcl-1 IRS and USP9x IRS, Spearman correlation coefficient $\rho$ was calculated after generating contingency tables for each WHO grade (JMP 11, Cary, NJ, USA).

Data analysis. Statistical significance was calculated by student $t$-test or oneway ANOVA test followed by a Bonferroni post-test where appropriate using GraphPad Software (San Diego, CA, USA).

\section{Conflict of Interest}

The authors declare no conflict of interest.

Acknowledgements. FW and JR and were supported by 'IZKF-Promotionskolleg' of the University Hospital Tuebingen, SMH by the Wilhelm-Sander-Stiftung (2011.083.1), VR and VJ by the DFG Research Training Group GRK1739 and by 'Deutsche Krebshilfe' (110355). We thank Heidrun Faltin and Angelika Warda for technical assistance and Dr. Mike Fay from Genesis CancerCare (New South Wales, Australia) for providing WKI primary glioblastoma cells.

1. Belka C, Rudner J, Wesselborg S, Stepczynska A, Marini P, Lepple-Wienhues A et al. Differential role of caspase- 8 and BID activation during radiation- and CD95-induced apoptosis. Oncogene 2000; 19: 1181-1190.

2. Youle RJ, Strasser A. The BCL-2 protein family: opposing activities that mediate cell death. Nat Rev Mol Cell Biol 2008; 9: 47-59.

3. Adams JM, Cory S. The Bcl-2 apoptotic switch in cancer development and therapy. Oncogene 2007; 26: 1324-1337.

4. Kelly PN, Strasser A. The role of Bcl-2 and its pro-survival relatives in tumourigenesis and cancer therapy. Cell Death Differ 2011; 18: 1414-1424.

5. Tagscherer KE, Fassl A, Campos B, Farhadi M, Kraemer A, Bock BC et al. Apoptosis-based treatment of glioblastomas with ABT-737, a novel small molecule inhibitor of Bcl-2 family proteins. Oncogene 2008; 27: 6646-6656.

6. van Delft MF, Wei AH, Mason KD, Vandenberg CJ, Chen L, Czabotar PE et al. The BH3 mimetic ABT-737 targets selective Bcl-2 proteins and efficiently induces apoptosis via Bak/ Bax if Mcl-1 is neutralized. Cancer Cell 2006; 10: 389-399.

7. Tse C, Shoemaker AR, Adickes J, Anderson MG, Chen J, Jin S et al. ABT-263: a potent and orally bioavailable Bcl-2 family inhibitor. Cancer Res 2008; 68: 3421-3428.

8. Huber S, Oelsner M, Decker T, zum Buschenfelde CM, Wagner M, Lutzny G et al. Sorafenib induces cell death in chronic lymphocytic leukemia by translational downregulation of Mcl-1. Leukemia 2011; 25: 838-847.

9. Trivigno D, Essmann F, Huber SM, Rudner J. Deubiquitinase USP9x confers radioresistance through stabilization of Mcl-1. Neoplasia 2012; 14: 893-904.

10. Maurer U, Charvet C, Wagman AS, Dejardin E, Green DR. Glycogen synthase kinase-3 regulates mitochondrial outer membrane permeabilization and apoptosis by destabilization of MCL-1. Mol Cell 2006; 21: 749-760.

11. Inuzuka H, Shaik S, Onoyama I, Gao D, Tseng A, Maser RS et al. SCF(FBW7) regulates cellular apoptosis by targeting MCL1 for ubiquitylation and destruction. Nature 2011; 471: 104-109.

12. Schwickart M, Huang X, Lill JR, Liu J, Ferrando R, French DM et al. Deubiquitinase USP9X stabilizes MCL1 and promotes tumour cell survival. Nature 2010; 463: 103-107.

13. Wick W, Hartmann C, Engel C, Stoffels M, Felsberg J, Stockhammer F et al. NOA-04 randomized phase III trial of sequential radiochemotherapy of anaplastic glioma with procarbazine, lomustine, and vincristine or temozolomide. J Clin Oncol 2009; 27: 5874-5880.

14. Tagscherer KE, Fassl A, Sinkovic T, Combs SE, Roth W. p53-dependent regulation of Mcl-1 contributes to synergistic cell death by ionizing radiation and the $\mathrm{Bcl}-2 / \mathrm{Bcl}-\mathrm{XL}$ inhibitor ABT-737. Apoptosis 2012; 17: 187-199.

15. Zhang C, Cai TY, Zhu H, Yang LQ, Jiang H, Dong XW et al. Synergistic antitumor activity of gemcitabine and ABT-737 in vitro and in vivo through disrupting the interaction of USP9X and Mcl-1. Mol Cancer Ther 2011; 10: 1264-1275. 
16. Peddaboina C, Jupiter D, Fletcher S, Yap JL, Rai A, Tobin RP et al. The downregulation of Mcl-1 via USP9X inhibition sensitizes solid tumors to Bcl-xl inhibition. BMC Cancer 2012; 12: 541.

17. Gratas C, Sery Q, Rabe M, Oliver L, Vallette FM. Bak and Mcl- 1 are essential for temozolomide induced cell death in human glioma. Oncotarget 2014; 5: 2428-2435.

18. Murphy AC, Weyhenmeyer B, Noonan J, Kilbride SM, Schimansky S, Loh KP et al. Modulation of Mcl-1 sensitizes glioblastoma to TRAIL-induced apoptosis. Apoptosis 2014; 19: 629-642.

19. Allen JC, Talab F, Zuzel M, Lin K, Slupsky JR. c-Abl regulates Mcl-1 gene expression in chronic lymphocytic leukemia cells. Blood 2011; 117: 2414-2422.

20. Ding Q, He X, Hsu JM, Xia W, Chen CT, Li LY et al. Degradation of Mcl-1 by beta-TrCP mediates glycogen synthase kinase 3-induced tumor suppression and chemosensitization. Mol Cell Biol 2007; 27: 4006-4017.

21. Wertz IE, Kusam S, Lam C, Okamoto T, Sandoval W, Anderson DJ et al. Sensitivity to antitubulin chemotherapeutics is regulated by MCL1 and FBW7. Nature 2011; 471: 110-114.

22. Zhong Q, Gao W, Du F, Wang X. Mule/ARF-BP1, a BH3-only E3 ubiquitin ligase, catalyzes the polyubiquitination of Mcl-1 and regulates apoptosis. Cell 2005; 121: 1085-1095

23. Wang B, Xie M, Li R, Owonikoko TK, Ramalingam SS, Khuri FR et al. Role of Ku70 in deubiquitination of Mcl-1 and suppression of apoptosis. Cell Death Differ 2014; 21: 1160-1169.

24. Cox JL, Wilder PJ, Gilmore JM, Wuebben EL, Washburn MP, Rizzino A. The SOX2interactome in brain cancer cells identifies the requirement of MSI2 and USP9X for the growth of brain tumor cells. PloS One 2013; 8: e62857.

25. Stegeman S, Jolly LA, Premarathne S, Gecz J, Richards LJ, Mackay-Sim A et al. Loss of Usp9x disrupts cortical architecture, hippocampal development and TGFbeta-mediated axonogenesis. PloS One 2013; 8: e68287.

26. Homan CC, Kumar R, Nguyen LS, Haan E, Raymond FL, Abidi F et al. Mutations in USPgX are associated with $\mathrm{X}$-linked intellectual disability and disrupt neuronal cell migration and growth. Am J Hum Genet 2014; 94: 470-478.

27. Mouchantaf R, Azakir BA, McPherson PS, Millard SM, Wood SA, Angers A. The ubiquitin ligase itch is auto-ubiquitylated in vivo and in vitro but is protected from degradation by interacting with the deubiquitylating enzyme FAM/USP9X. J Biol Chem 2006; 281: 38738-38747.

28. Taya S, Yamamoto T, Kanai-Azuma M, Wood SA, Kaibuchi K. The deubiquitinating enzyme Fam interacts with and stabilizes beta-catenin. Genes Cells 1999; 4: 757-767.

29. Watson RL, Spalding AC, Zielske SP, Morgan M, Kim AC, Bommer GT et al. GSK3beta and beta-catenin modulate radiation cytotoxicity in pancreatic cancer. Neoplasia 2010; 12 . 357-365.

30. Azakir BA, Angers A. Reciprocal regulation of the ubiquitin ligase Itch and the epidermal growth factor receptor signaling. Cell Signal 2009; 21: 1326-1336.

31. Fedrigo CA, Grivicich I, Schunemann DP, Chemale IM, dos Santos D, Jacovas T et al. Radioresistance of human glioma spheroids and expression of HSP70, p53 and EGFr. Radiat Oncol 2011; 6: 156.

32. Zheng X, Zhai B, Koivunen P, Shin SJ, Lu G, Liu J et al. Prolyl hydroxylation by EgIN2 destabilizes FOXO3a by blocking its interaction with the USP9x deubiquitinase. Genes Dev 2014; 28: 1429-1444.
33. Krajewski S, Krajewska M, Ehrmann J, Sikorska M, Lach B, Chatten J et al. Immunohistochemical analysis of $\mathrm{Bcl}-2, \mathrm{Bcl}-\mathrm{X}, \mathrm{Mcl}-1$, and $\mathrm{Bax}$ in tumors of central and peripheral nervous system origin. Am J Pathol 1997; 150: 805-814.

34. Leverson JD, Zhang H, Chen J, Tahir SK, Phillips DC, Xue J et al. Potent and selective small-molecule MCL-1 inhibitors demonstrate on-target cancer cell killing activity as single agents and in combination with ABT-263 (navitoclax). Cell Death Dis 2015; 6: e1590.

35. Pareja F, Macleod D, Shu C, Crary JF, Canoll PD, Ross AH et al. PI3K and Bcl-2 inhibition primes glioblastoma cells to apoptosis through downregulation of Mcl-1 and Phospho-BAD. Mol Cancer Res 2014; 12: 987-1001.

36. Levesley J, Steele L, Taylor C, Sinha P, Lawler SE. ABT-263 enhances sensitivity to metformin and 2-deoxyglucose in pediatric glioma by promoting apoptotic cell death. PloS One 2013; 8: e64051.

37. Oltersdorf T, Elmore SW, Shoemaker AR, Armstrong RC, Augeri DJ, Belli BA et al. An inhibitor of Bcl-2 family proteins induces regression of solid tumours. Nature 2005; 435 : $677-681$.

38. Certo M, Del Gaizo Moore V, Nishino M, Wei G, Korsmeyer S, Armstrong SA et al. Mitochondria primed by death signals determine cellular addiction to antiapoptotic BCL-2 family members. Cancer Cell 2006; 9: 351-365.

39. Chen HC, Kanai M, Inoue-Yamauchi A, Tu HC, Huang Y, Ren D et al. An interconnected hierarchical model of cell death regulation by the BCL-2 family. Nat Cell Biol 2015; 17: $1270-1281$.

40. Miyashita T, Reed JC. Tumor suppressor p53 is a direct transcriptional activator of the human bax gene. Cell 1995; 80: 293-299.

41. Oda E, Ohki R, Murasawa H, Nemoto J, Shibue T, Yamashita T et al. Noxa, a BH3-only member of the Bcl-2 family and candidate mediator of p53-induced apoptosis. Science 2000 288: 1053-1058.

42. Lowe SW, Schmitt EM, Smith SW, Osborne BA, Jacks T. p53 is required for radiationinduced apoptosis in mouse thymocytes. Nature 1993; 362: 847-849.

43. England B, Huang T, Karsy M. Current understanding of the role and targeting of tumor suppressor p53 in glioblastoma multiforme. Tumour Biol 2013; 34: 2063-2074.

44. Ontikatze T, Rudner J, Handrick R, Belka C, Jendrossek V. Dihydroartemisinin is a hypoxiaactive anti-cancer drug in colorectal carcinoma cells. Front Oncol 2014; 4: 116

(c) Cell Death and Disease is an open-access journal published by Nature Publishing Group. This work is licensed under a Creative Commons Attribution 4.0 International License. The images or other third party material in this article are included in the article's Creative Commons license, unless indicated otherwise in the credit line; if the material is not included under the Creative Commons license, users will need to obtain permission from the license holder to reproduce the material. To view a copy of this license, visit http://creativecommons.org/licenses/by/4.0/

Supplementary Information accompanies this paper on Cell Death and Disease website (http://www.nature.com/cddis) 